\title{
The Ecosystem of Patient Support Programs (PSPs) in India
}

\author{
Shubhra Seal, Arun Kumar S, Gramle Amol, Nafisa Vaz
}

\begin{abstract}
The incidence and prevalence of non-communicable diseases are on the rise. Such diseases require prolonged treatment and it is of utmost importance to be compliant to treatment. Pharmaceutical companies are moving from traditional marketing to "beyond the pill" marketing to foster patient centricity. These companies also have a motive to conduct sustained sales of their products for the prolonged treatment tenures. For this reason, pharmaceutical companies have come up with support programs to promote treatment adherence. In India, support programs are also conducted by the Government, peer support groups, home healthcare and animal-assisted therapy. Detailed primary research and its analysis have been conducted to look at different parameters discussed in the study. A model for an ideal patient support program has been provided.

Keywords: Patient Support, Adherence, Diabetes, Cancer, Pharmaceutical Company, Patient Assistance.
\end{abstract}

\section{INTRODUCTION}

\section{P} provide personalized support and tailored intervention to improve patient health outcomes. These programs ensure adherence to medicines and treatment regimens by enabling patients to learn more about their condition, monitor their progress and track symptoms as they progress through their health journey.

Though the healthcare industry in India has seen such a booming growth the total industry size is estimated to touch $\$ 372$ billion by 2022 [1], with exponential strides in research and development. The Government and private sector trying to improve access to healthcare for the less fortunate, it still cannot be claimed that the healthcare delivery systems of India are effective.

Healthcare providers are burdened with cases and are, therefore, unable to provide personalized care to their patients, impart education to patients about their condition, the medication that they are prescribed and provide support throughout the tenure of treatment. To bridge this gap, patient support programs are run to aid patients focusing on the following factors.

Manuscript received on June 08, 2021

Revised Manuscript received on June 10, 2021.

Manuscript published on June 30, 2021.

* Correspondence Author

Shubhra Seal, Management Trainee, Healthcare and Life sciences, Hexaware Technologies, Pune, India. Email sealcapricorn1997@gmail.com

Arun Kumar S*, Intern, Consulting and Solutioning BioQuest Solutions Pvt. Ltd., Bengaluru, India. Email: arun.s@bioquestglobal.com

Dr Amol Gramle, Vice President, Consulting and Solutioning, BioQuest Solutions Pvt. Ltd., Bengaluru, India.

Email: gramle.amol@bioquestglobal.com

Nafisa Vaz, Professor, Goa Institute of Management, Goa, India. Email: nafisa.vaz@gmail.com

(C) The Authors. Published by Blue Eyes Intelligence Engineering and Sciences Publication (BEIESP). This is an open access article under the CC BY-NC-ND license (http://creativecommons.org/licenses/by-nc-nd/4.0/)
The main consumer for the healthcare industry is the patient. Players in the healthcare industry strive to perform for the better health outcomes of patients. Pharmaceutical companies are shifting their trends to being patient-centric. Many factors have contributed to the advent of patient support programs in India over the years.

Nowadays, patients are well-informed about diseases and want to be actively involved in making decisions about their health outcomes. The rise of the internet and access to social media has made it much easier for patients to know about their conditions.

Due to lack of time, healthcare providers are unable to provide information to the patients regarding the medication that they take. For example, first-time insulin takers are apprehensive about how the insulin pen works and fear of injectables makes it even worse for such patients who are not guided completely. Assistance to use the device and imparting confidence to the first-time insulin taker is necessary.

Many patients find it difficult to afford treatments and procedures. In such cases, the provision of healthcare can be made free to ensure better health outcomes.

The Indian pharmaceutical industry has moved from being focused on the "the pill" to "beyond the pill".

Healthcare in India is no longer restricted to providing the right drug to cure a disease. Indian pharmaceutical companies have come a long way from their traditional setup where they focused only on investing time, money and manpower in researching, developing and selling their drugs [2].

They are extending a helping hand and have come in the chain to support patients to ensure they are adherent to their medication regimens so that they can combat their conditions better and also create a brand value for themselves by promoting the idea of "patient centricity [3].

Support is not only provided by pharmaceutical companies but also by NGOs who provide support in the form of counselling and peer support. Home healthcare services have also gained a considerable amount of popularity as the patient recuperates from an illness in the comfort of his or her own home.

To better understand PSPs (Patient Support Programs) in India, the PSPs run by top MNCs in India and top Indian MNCs were studied in this article.

\section{METHODS AND MATERIALS}

BioQuest Solutions Pvt. Ltd. conducted this study during the summer of 2019 to understand the impact of PSPs on the Indian landscape.

Published By:

Blue Eyes Intelligence Engineering \& Sciences Publication (BEIESP)

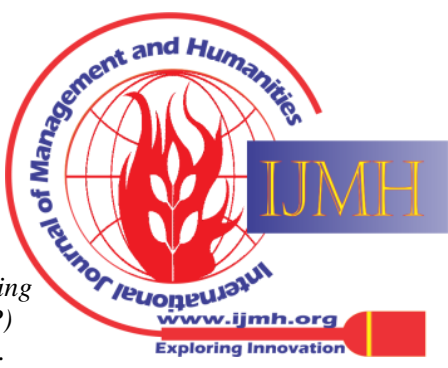




\section{A. Questionnaire Preparation}

A Questionnaire consisting of about 19 questions was prepared according to which the interviews were conducted. This questionnaire contained questions on the year of the start of the program, reasons for the initiation of the program, sourcing of the program, patient enrollment, process and functioning of the program, number of patients covered, challenges faced by them in the implementation.

\section{B. Data Sample}

For this study, 23 programs from 9 companies were identified. Out of the 9 companies, 4 were multi-national companies namely Glaxo Smith Kline, Roche, Sanofi, and Janssen Pharmaceuticals followed by 5 Indian multinational companies - Biocon, Cipla, Dr. Reddy's Laboratories, Emcure Pharmaceuticals and Lupin. Very limited information could be made public on these programs since PSP data is extremely confidential for a pharmaceutical company and every program follows a different strategy. This serves as a source of competitive advantage.

\section{Statistical Analysis}

To analyze the results of this study, Descriptive statistics in terms of frequency and percentage were utilized.

\section{RESULTS AND DISCUSSIONS}

Table I - Programs studied from companies in India and the number of patients covered in respective programs as of 2019

\begin{tabular}{|c|c|c|}
\hline $\begin{array}{l}\text { Name of the } \\
\text { Company }\end{array}$ & Name of the program & $\begin{array}{c}\text { No.of } \\
\text { Patients } \\
\text { covered } \\
\end{array}$ \\
\hline Glaxo Smith Kline & $\begin{array}{l}\text { Calcium deficiency } \\
\text { No Hypothyroidism } \\
\text { Antibiotic resistance } \\
\text { Toll-free number } \\
\text { Mission health }\end{array}$ & $\begin{array}{l}\text { No data } \\
\text { available for } \\
\text { any of the } \\
\text { programs }\end{array}$ \\
\hline $\begin{array}{l}\text { Janssen } \\
\text { Pharmaceuticals }\end{array}$ & $\begin{array}{l}\text { Nutrition support } \\
\text { initiative } \\
\text { Patient advocacy } \\
\text { Active finding } \\
\text { Contact screening } \\
\text { Drug-resistant } \\
\text { tuberculosis linkage } \\
\text { model }\end{array}$ & $\begin{array}{l}\text { No data } \\
\text { available for } \\
\text { any of the } \\
\text { programs }\end{array}$ \\
\hline Roche & Blue tree program & 4800 \\
\hline Sanofi & Saath 7 & 412000 \\
\hline Biocon & $\begin{array}{l}\text { Patient assistance } \\
\text { program for Basalog } \\
\text { insulin }\end{array}$ & 23520 \\
\hline Cipla & $\begin{array}{l}\text { Patient assistance } \\
\text { program for Hep B } \\
\text { patients }\end{array}$ & 1680 \\
\hline $\begin{array}{l}\text { Dr. Reddy's } \\
\text { laboratories }\end{array}$ & $\begin{array}{l}\text { Vega club - for HBD } \\
\text { ASSIST - for hair fall } \\
\text { Liv positive - for Hep B } \\
\text { Sparsh - for cancer }\end{array}$ & $\begin{array}{c}5000 \\
\begin{array}{c}\text { No data } \\
\text { available }\end{array} \\
\text { No data } \\
\text { available } \\
5000\end{array}$ \\
\hline
\end{tabular}

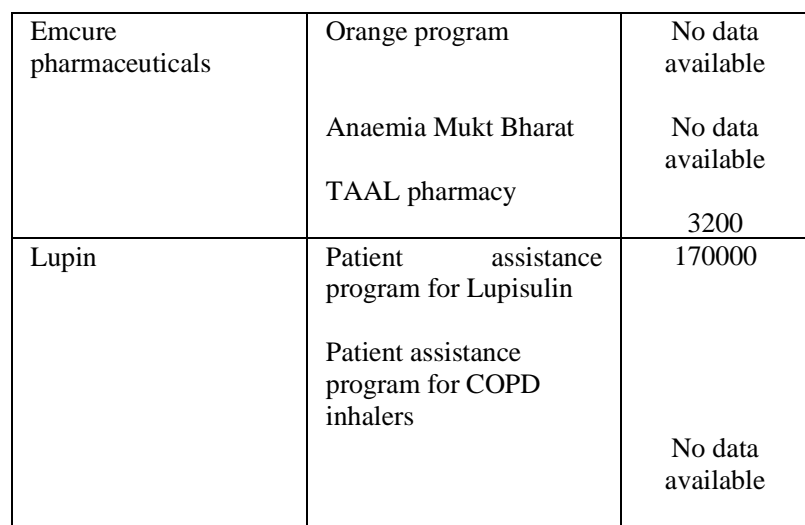

Table I, holds the different PSPs conducted by MNCs and the number of participants for the PSPs whenever available.

With the information collected during the interviews based on the questionnaire, the following statistical analysis were carried out.

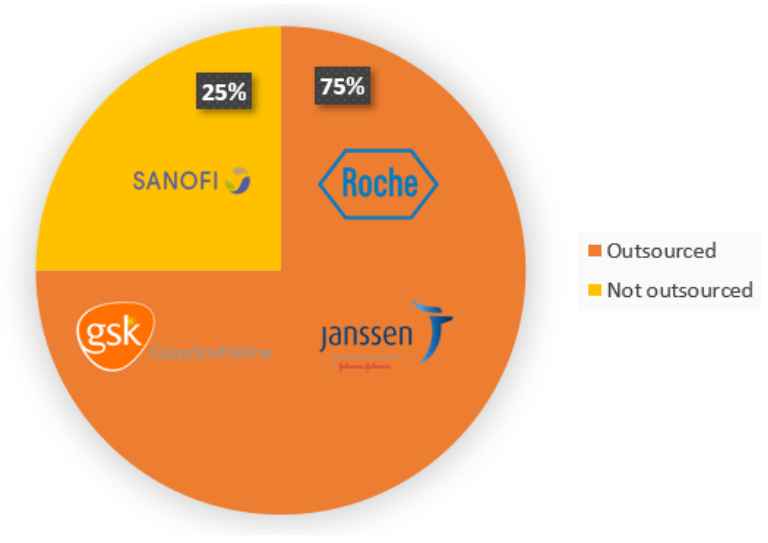

Fig.1: Percentage of MNCs who have outsourced PSPs

From Fig.1, 75\% of the MNCs such as Roche, GSK, Janssen were outsourcing their Patient Support Programs. Only 25\% of the MNCs, Sanofi was organizing PSPs with their team.

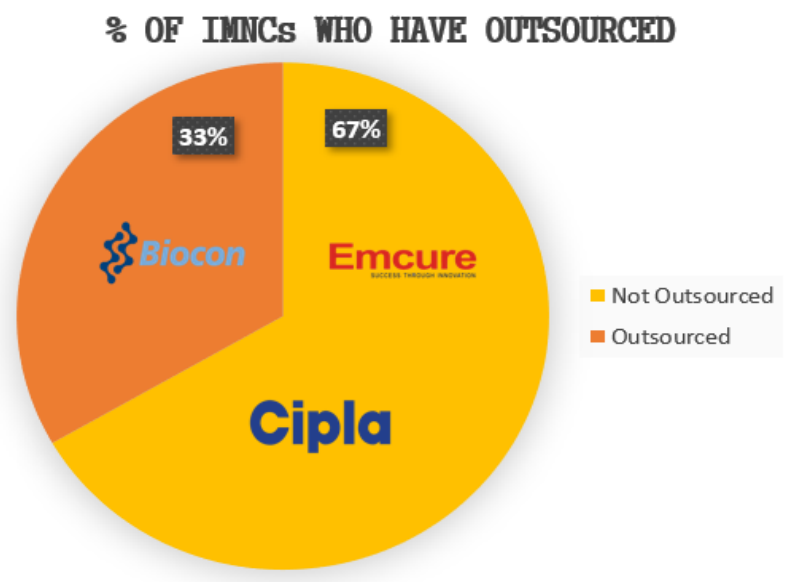

Fig.2: Percentage of Indian Multinational Companies who have outsourced PSPs

Published By:

Blue Eyes Intelligence Engineering

\& Sciences Publication (BEIESP)

33 (C) Copyright: All rights reserved.

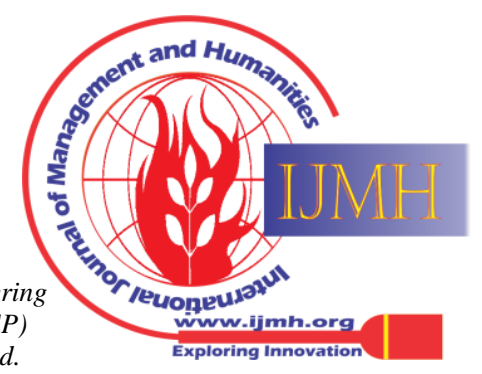


From Fig.2, 67\% of the Indian Multinational companies such as Emcure and Cipla have completely done the PSPs with their in-house team whereas only 33\%, Biocon has completely outsourced PSPs.

A clear reason was not elucidated by the companies due to confidentiality reasons. A probable reason for complete outsourcing by the MNCs (fig.1) after analysing was found to be that these agencies are completely devoted to the flawless functioning of the program, and this reduces the time required and hiring cost required for a separate team within the organisation.

But with Indian multinational companies (fig.2), most didn't outsource probably by utilizing pre-existing internal teams such as sales and marketing to follow up the Patient Support programs, thereby removing even the cost of outsourcing.

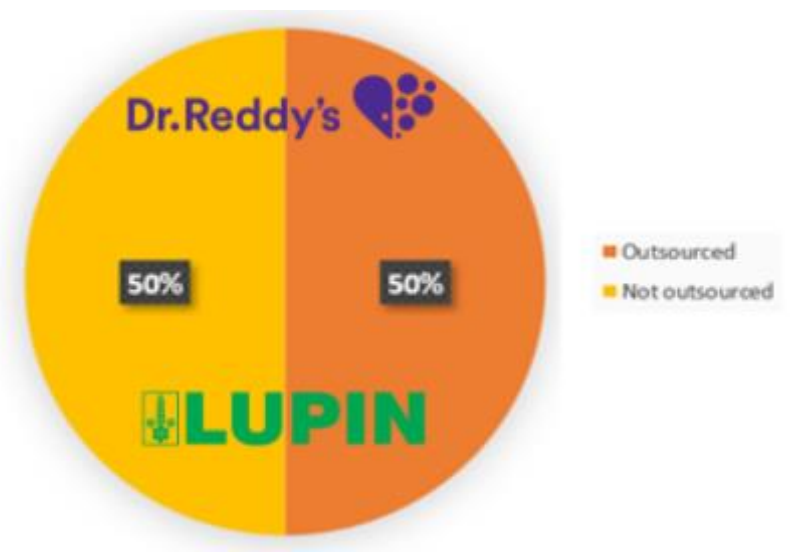

Fig.3: Indian Multinational Companies who have 50-50 PSPs sourcing

Fig.3, shows the outsourcing model of Dr. Reddy's laboratories and Lupin follow a mixed model of outsourcing where $50 \%$ of their programs studied were run by the inhouse team and 50\% were outsourced to third party agencies. A probable explanation for this can be due to the non-availability of specialized teams in their target PSPs or may be due to a lack of technical skills with their in-house team.

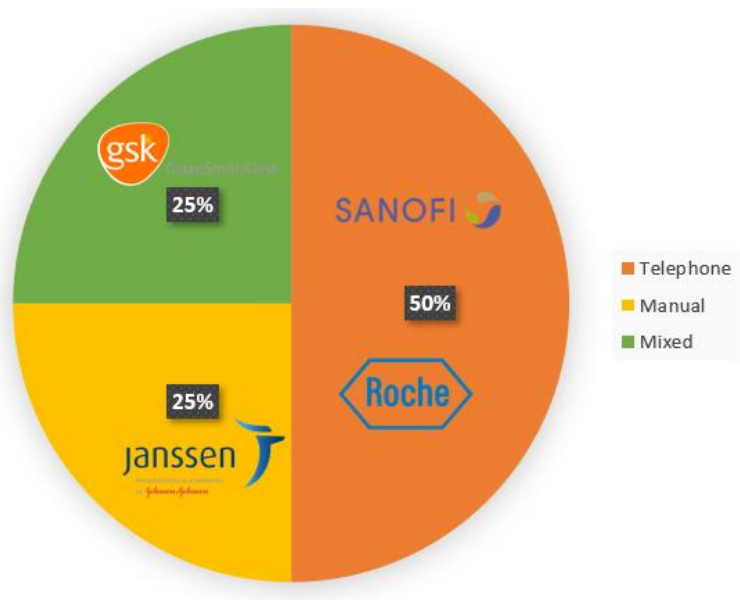

Fig.4: Mode of Engagement by MNCs

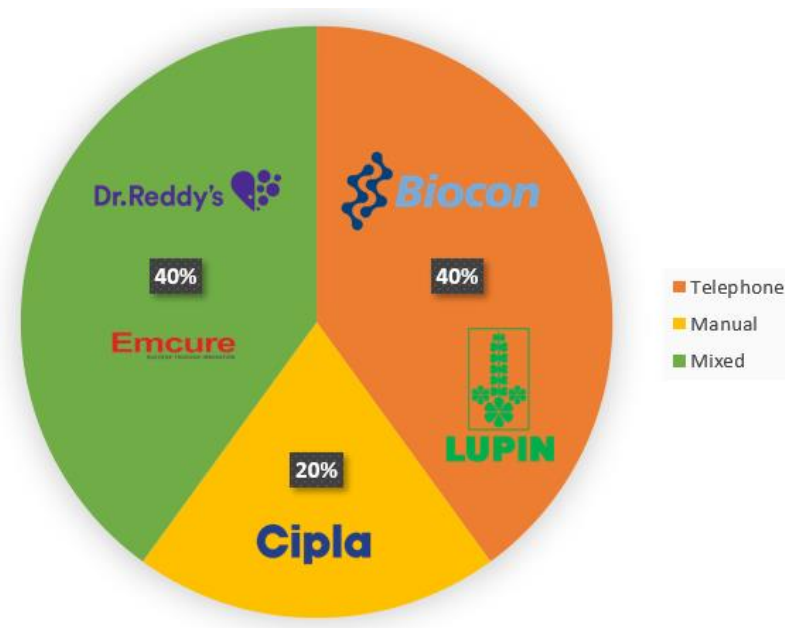

Fig.5: Mode of Engagement by Indian Multinational Companies

From Fig.4 and Fig.5, it is clear that the preferred mode of engagement by MNCs to the patient is through telephone for both multi-national companies and Indian multi-national companies. The basic procedure followed in this case is that, once the patient finished the consultation with his or her treating physician, the physician will give a contact number of the support program executive on which they could call and get themselves enrolled in the PSP.

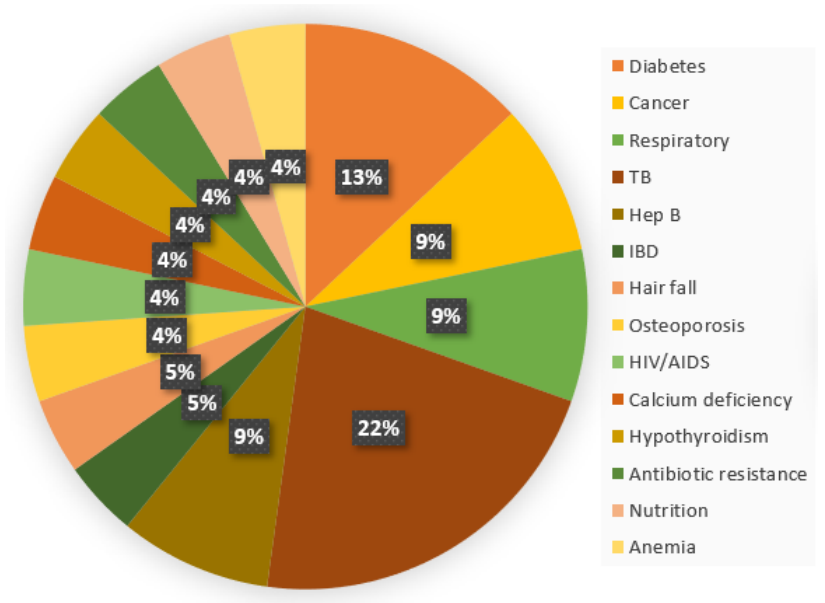

Fig.6: Therapeutic areas addressed in this study

Fig.6 shows the therapeutic areas addressed across all the 23 programs studied for this article. However, this data might be skewed since major programs conducted in India as well as globally are in the areas of diabetes and cancer Since 5 programs related to TB were studied in this article, the pie-chart portrays a greater segment for programs run for TB as $22 \%$, followed by $13 \%$ towards Diabetes, $9 \%$ each for Cancer, Respiratory diseases and Hepatitis B.

After gaining knowledge about the expectations of patients by interviewing them and analyzing the gaps in the programs studied, the following are some recommendations for major areas of focus, Cancer and Diabetes.

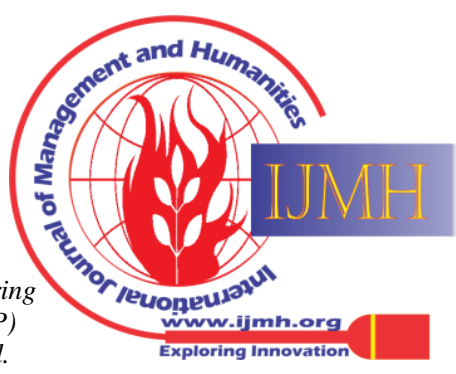




\section{From the Company's and Program's Perspective:}

The patient journey should be studied before launching a patient support program. After studying the journey, gaps should be identified and to address these gaps a support program should be launched.

Support programs should be outsourced to a third-party agency. Running a successful patient support program requires sustained efforts. A team dedicated to the running of this program should be set up. However, an internal team in the company should be in place to coordinate with the outsourced agency [4].

An audit should be conducted, rather than intermittent document checks, at regular intervals to get a clear picture of the patient retention statistics.

To tackle different patients differently, patient profiling is an option. Patient profiling can be done according to the patient's behaviour towards the program or based on any other condition that the patient might be having to provide personalized care.

\section{From the Patient's Perspective:}

Financial assistance to be provided to patients either as a co-pay assistance or offering free products for one cycle after the patient has purchased two cycles of drugs.

Provision of emotional counselling services either by a separate team in the support program or by having tie-ups with NGOs who offer such services [5].

Education and counselling the family members of the patients about the condition.

Education of the caregivers attending to patients and counselling to the family members about the condition

$24 * 7$ call support team to address any doubts the patients might have.

Peer support groups moderated by doctors with which the support team is associated [4].

Discounted home delivery of medicines to the patient's place. Tie-ups with pathology laboratories for discounted blood sugar testing.

Commencement of support program for patients on oral medication for diabetes. Follow up calls to ensure adherence and stock checking of insulin with patients.
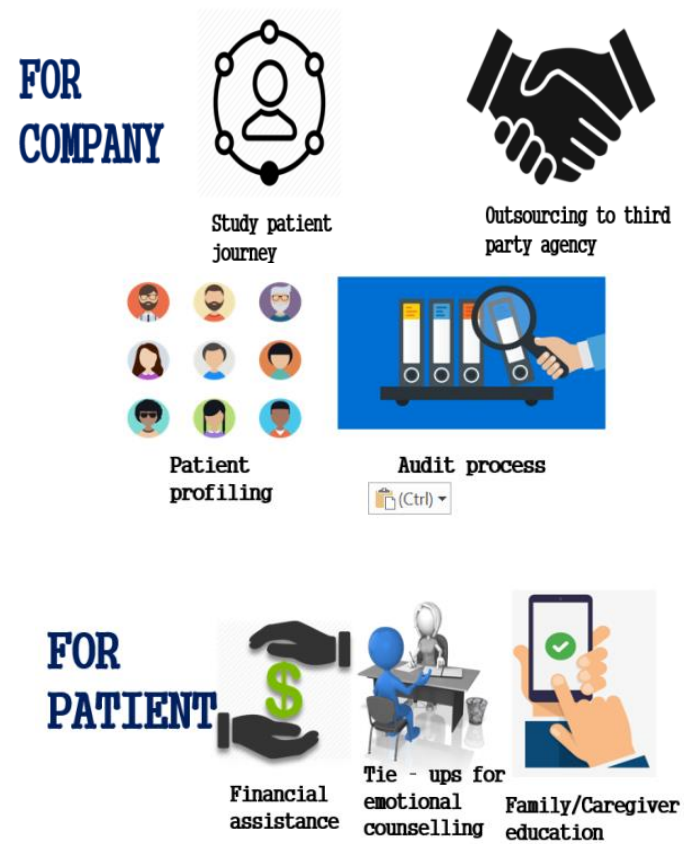

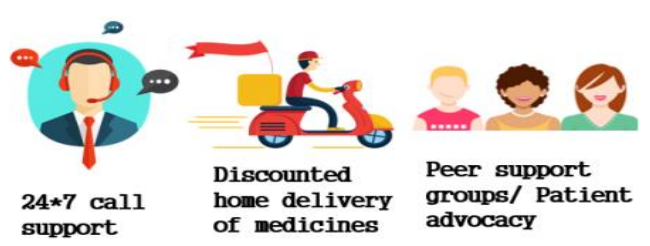

Fig.7: Ideal Patient Support Program model

\section{CONCLUSION}

From this research, we could conclude that outsourcing of PSPs has an advantage over an in-house team as it reduces the cost of initiation and management along with providing speciality specific offers to customize the PSPs. The telephonic mode of engagement with the patients is much preferred by both company and patients thus providing an easier way to connect where patients could be free to ask for financial assistance, counselling, patient education and patient advocacy as they need.

\section{REFERENCES}

1. Department for Promotion of Industry and Internal Trade (DPIIT), RNCOS Reports, Media Reports, Press Information Bureau (PIB), Union Budget 2021-22.

2. Griffiths C, Motlib J, Azad A, Ramsay J, Eldridge S, Feder G, Khanam R, Munni R, Garrett M, Turner A, Barlow J. Randomised controlled trial of a lay-led self-management programme for Bangladeshi patients with chronic disease. British Journal of General Practice. 2005 Nov 1;55(520):831-7.

3. Obreli-Neto PR, Guidoni CM, de Oliveira Baldoni A, Pilger D, Cruciol-Souza JM, Gaeti-Franco WP, Cuman RK. Effect of a 36-month pharmaceutical care program on pharmacotherapy adherence in elderly diabetic and hypertensive patients. International journal of clinical pharmacy. 2011 Aug 1;33(4):642-9.

4. Chujo M, Kigawa J, Okamura H. Psychological factors and characteristics of recurrent breast cancer patients with or without psychosocial group therapy intervention. Yonago acta medica. 2011 Dec;54(4):65.

5. Bui LL, Last L, Bradley H, Law CH, Maier BA, Smith AJ. Interest and participation in support group programs among patients with colorectal cancer. Cancer nursing. 2002 Apr 1;25(2):150-7.

\section{AUTHORS PROFILE}

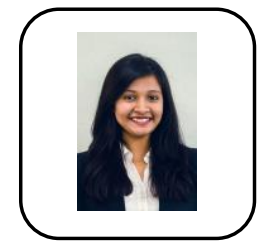

Shubhra Seal Currently employed with Hexaware Technologies as a Management Trainee for Healthcare and Life sciences vertical. Educational Background with Post Graduate Diploma in Healthcare Management from Goa Institute of Management; Bachelor of Science in Microbiology from Pune University. In addition to being a corporate professional, I am a creative enthusiast with an immense passion for dancing, writing, photography and graphic designing. Completed multiple certifications in topics like integrated marketing communications, digital marketing, graphic designing, cloud computing, power BI, communication skills, design thinking from Coursera \& Udemy.

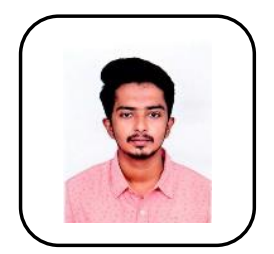

Arun Kumar S Currently interning at BioQuest Solutions Pvt. Ltd under the Consulting and Solutioning (Pre-Sales) team. Pursuing M.Sc. Biotechnology in Vellore Institute of Technology, Vellore. I am an enthusiastic and curious learner who is ready to explore the unknown. Like to solve problems.
Published By:

Blue Eyes Intelligence Engineering

\& Sciences Publication (BEIESP)

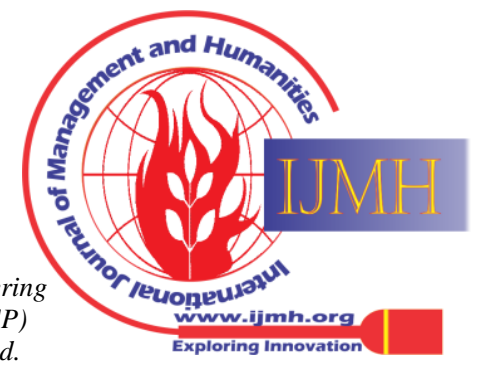


Participated in various events for knowledge enhancement. Presented a paper during the 19th International Conference on Science, Engineering and Technology (ICSET) at Vellore Institute of Technology. Certifications include High Impact Business writing, Artificial Intelligence, Excel Skills from Coursera and strategic thinking from LinkedIn.

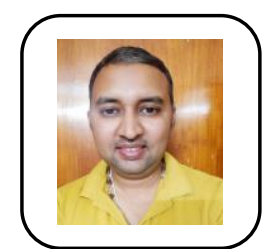

Dr Gramle Amol Currently employed BioQuest Solutions Pvt. Ltd as Vice President for Consulting and Solutioning (Pre-Sales) team. Educational background with Bachelor of Medicine, Bachelor of Surgery (MBBS) followed by Doctor of Medicine (MD), Clinical Pharmacology and Therapeutics at Rajendra Institute of Medical Sciences and Research Center and Executive Management Degree in Business Analytics and Strategy at Indian Institute of Management, Indore. He has published research articles in various National and International journals. He is a Life Member in ISPOR - The Professional Society for Health Economics and Outcomes Research and was awarded University Gold Medal- MD Pharmacology in Ranchi University.

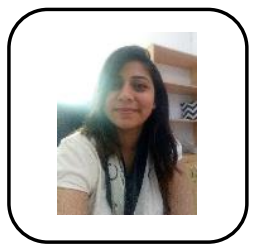

Prof. Nafisa Vaz, is currently working as a faculty with Goa Institute of Management, has experience of over 10 years of in the area of healthcare. She has done her MBA(HCM), PGDCRM and currently pursuing her $\mathrm{PhD}$. Her rich corporate experience is concentrated in the area of Operations and Healthcare Branding. She has extensive experience working with hospitals, diagnostics and the Insurance Industry. She has worked with brands like Manipal Health Enterprise Ltd, Apollo Group, SRL Diagnostics, Goa Ayurvedic Hospital and ICICI Prudential Health Insurance. Having worked in various sectors of the healthcare industry she brings with her deep insights into the best practices followed in the healthcare industry. She has carried out consulting assignments for several reputed private organizations and the government including NHA and the WHO for projects on the Ayushman Bharat Scheme launched by the Government of India. She has published papers in National and International journals and has several book chapters to her credit. Her research interests are mainly in the area of Services Marketing, Branding and Design thinking

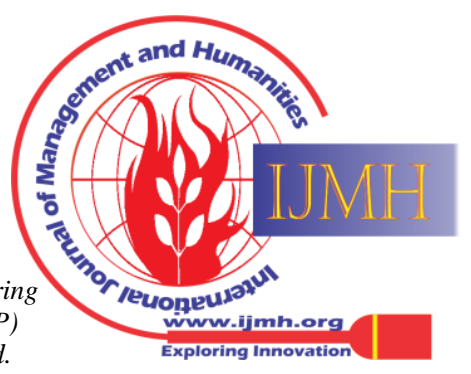

